\title{
Mesoscale Variation in Diabatic Heating around Sumatra, and Its Modulation with the Madden-Julian Oscillation
}

\author{
Claire L. Vincent AND Todd P. LANE \\ School of Earth Sciences and ARC Centre of Excellence for Climate Extremes, The University of Melbourne, \\ Melbourne, Victoria, Australia
}

(Manuscript received 23 December 2017, in final form 15 May 2018)

\begin{abstract}
Diabatic heating in the Maritime Continent region is controlled by a unique blend of mesoscale variability associated with steep topography and complex coastlines and intraseasonal variability associated with propagating planetary-scale disturbances. In this study, the diabatic heating from a 10 -yr austral summer simulation over the Maritime Continent with a 4-km horizontal grid length is analyzed with respect to diurnal, spatial, and intraseasonal variations. Results are compared, where possible, to analogous estimates from the TRMM precipitation radar. We show that the heating budget is largely a balance between latent heating and vertical advection, with rays of heating and cooling extending upward and outward from the coast evident in the advection terms, consistent with the gravity wave representation of the tropical sea breeze. By classifying rainfall into convective and stratiform components, it is shown that simulated convective heating over Sumatra peaks in MJO phases 2 and 3, while simulated stratiform heating peaks in phase 4. Similarly, spectral latent heating estimates from the TRMM Precipitation Radar show that stratiform heating peaks in phases 3 and 4 , while convective heating peaks in phases 2 and 3. It is also shown that stratiform precipitation plays a greater role in offshore precipitation during the night, albeit with embedded convective cores, than over the land during the day. These results emphasize the importance of achieving a realistic representation of convective and stratiform processes in high-resolution simulations in the tropics, both for total rainfall estimates and for realistic latent heating.
\end{abstract}

\section{Introduction}

The weather and climate of the Maritime Continent is dominated by both intraseasonal-scale and mesoscale variability. Numerous studies have found evidence to support the modulation of the diurnal precipitation cycle by intraseasonal-scale variability, including Houze et al. (1981), Rauniyar and Walsh (2013), Fujita et al. (2011), Peatman et al. (2014), Birch et al. (2016), Vincent and Lane (2016a), and Vincent and Lane (2017). A recurring finding in these studies is that the diurnal precipitation cycle tends to be suppressed by the onset of background conditions of cloudiness and convection, possibly with the added contribution of large-scale background winds affecting the strength of local land and sea breezes. For example, Peatman et al. (2014) used observational evidence from the TRMM satellite to show that the diurnal precipitation cycle over the land reached a maximum ahead of the main envelope of the Madden-Julian oscillation

Corresponding author: Claire L. Vincent, claire.vincent@ unimelb.edu.au
(MJO). This maximum was shown to be related to the moistening conditions ahead of the onset of the main envelope of cloudiness and convection (Birch et al. 2016) and was found to be a persistent signal across all the major islands of the Maritime Continent (Vincent and Lane 2017). These studies have motivated attempts to understand intrascale feedbacks in the region, in particular in the upscale direction, due in part to the possibility of a dynamical influence on larger-scale climate variability. For example, Oh et al. (2013) found that intraseasonal variability became stronger when the diurnal cycle was suppressed.

The diurnal precipitation cycle in convection-permitting models reflects the evolution of microphysical cloud processes during the day and night. Several studies have used convection-permitting models to successfully simulate key aspects of the diurnal and MJO-scale variability in the Maritime Continent, including Fujita et al. (2011), who studied the evolution of the MJO over Sumatra using the Nonhydrostatic Icosahedral Atmospheric Model (NICAM) with a horizontal grid length of $7 \mathrm{~km}$, Vincent and Lane (2016a) and Vincent and Lane (2017) who simulated the changes in the diurnal cycle over New Guinea and the 
whole Maritime Continent using the Weather Research and Forecasting (WRF) Model with a horizontal grid length of $4 \mathrm{~km}$, and Birch et al. (2016) who simulated a 10-yr period over Sumatra with a horizontal grid spacing of $4.5 \mathrm{~km}$ using the Met Office Unified Model. While these models all reproduce the observed tendency for a suppressed diurnal cycle during the early part of the MJO active phase, the precise timing and amplitude of the diurnal cycle remains a source of uncertainty.

Simulated microphysical processes (such as condensation and evaporation of liquid water or freezing and melting of cloud hydrometeors) are critical not only because of their relationship to local precipitation, but because of the latent heat that they release (Marinescu et al. 2016). This diabatic heating sits at the nexus of mesoscale and intraseasonal-scale interactions in the tropics. The diabatic heating arising from cloud processes may be broadly categorized as convective or stratiform in origin, each of which have fundamentally different characteristic vertical latent heating profiles (Ahmed et al. 2016). Deep convective precipitation is associated with heating throughout the troposphere, while deep stratiform precipitation from thunderstorm anvils is characterized by heating aloft with a layer of cooling below, as precipitation falls through unsaturated air and evaporates (Houze 2004). Other precipitating clouds, such as shallow clouds, also have distinctive heating profiles. These differing heating profiles mean that in order to understand and simulate the upscale dynamic or thermodynamic impact of tropical convection, it is critical to simulate the right type of precipitation (or at least the right heating profile), rather than just the correct surface rainfall amount. Moreover, even though there is an approximate balance between the large-scale mean diabatic heating and radiative cooling, details of the diabatic heating are critical in determining the dynamical response on a range of scales.

In Vincent and Lane (2017) it was suggested that errors in the timing of the diurnal precipitation cycle in high-resolution convection-permitting simulations over the Maritime Continent could be partly related to the partitioning between convective and stratiform precipitation. It was shown that the observed diurnal precipitation cycle reached a peak in the late afternoon, before flattening out and slowly decreasing during the night. In contrast, the modeled diurnal precipitation cycle reached a peak in the afternoon, before steeply decreasing in the evening, with less of a tendency to flatten out. This study emphasized that the diurnal precipitation cycle is actually a combination of rain from convective and stratiform processes. In a coarse-resolution model with parameterized convection, there is an explicit separation of "large scale," (or resolved) and "convective," (or parameterized) precipitation. In this case, adjustments to the heat and moisture profile via the convective parameterization work together with microphysics to incorporate the upscale impact of deep tropical convection. These rainfall categories may be loosely analogous to stratiform and convective rain, but the delineation is by no means clear, particularly for a model in the "gray zone" where some convective processes will be resolved explicitly. In a convection-permitting model, there is no such obvious delineation into rainfall types, since all precipitation is generated via the cloud microphysics scheme. It is reasonable to assume, however, that processes analogous to convective and stratiform rain exist within a convectionpermitting model.

Heating and moistening from cloud microphysics is difficult to observe. Yanai et al. (1973) used a network of radio soundings to estimate the rate of change of heat and moisture from horizontal and vertical wind speed and temperature profiles, based on the residual of the heating budget. Xie et al. (2010) estimated heating for suppressed, clear, and break monsoon conditions near Darwin, Australia, and Tang et al. (2016) estimated heating budgets over the Amazon region using a constrained variational analysis approach. Lin et al. (2004) used a similar approach to estimate heating over the Indian Ocean with the passage of the MJO. They partitioned the heating into convective, stratiform, and radiative components, and found that with the onset of the MJO, the stratiform rainfall anomalies lagged the convective anomalies by a few days.

In most numerical weather or climate models, the diabatic heating is calculated as an explicit potential temperature tendency. Depending on the formulation of the model, the heating will arise from the microphysics scheme, the cumulus scheme, the planetary boundary layer scheme, and the radiation scheme. This explicit gridded expression of the heating terms, which is nearly impossible to achieve from observations, has been exploited in several studies that have attempted to characterize changes in diabatic heating with various large-scale environments. For example, Ahmed et al. (2016) used the WRF Model to estimate profiles of diabatic heating for convective and stratiform rainfall, where rainfall types were diagnosed by the size characteristics of the rainfall features. They used the resulting profiles to create lookup tables for diagnosing convective and stratiform latent heating from satellite precipitation estimates. Cao and Zhang (2017) used observed heating profiles to correct the heating terms in a climate-scale model, resulting in a better representation of the MJO and providing important evidence of interscale feedback in the upscale direction. Klingaman et al. (2015) examined diabatic heating and net moistening in 20-day hindcasts in a range of GCMs during two MJO events, and found no distinctive pattern in the diabatic heating profiles 
for different rain-rate quartiles in the models that produced the most realistic MJO structure. Nonetheless, the variety of shapes of heating profiles that they found is indicative of the substantial spread of model representations of rainfall types and their associated latent heating processes.

In this study, the heating budget over the Maritime Continent is examined in convection-permitting model simulations. The gridded model data afford the opportunity to calculate a fully balanced heating budget, which is shown to be nearly a balance between microphysics and advective tendencies, with evidence of gravity waves detected in the residual of these terms. Diabatic heating from microphysics is separated into contributions from convective and stratiform precipitation, which are seen to peak in different phases of the MJO. Where possible, results are compared with analogous results from the TRMM spectral latent heating (SLH) product (Shige et al. 2004). These results provide evidence that the correct partitioning of convective and stratiform precipitation is critical to simulating a realistic latent heating profile.

The remainder of this paper is arranged as follows: in section 2, the simulated and satellite datasets are described, and the methodologies for rainfall classification and calculation of the simulated heating budget are presented. In section 3 , precipitation and potential temperature tendencies from the model are examined, then conditionally averaged by MJO phase and spatially averaged over an area around Sumatra or interpolated onto a cross section through Sumatra. Precipitation and diabatic heating are compared with analogous results from TRMM estimates. Discussions and conclusions are presented in sections 4 and 5.

\section{Methods and data}

\section{a. Simulations}

The model-derived analysis in this paper is from a 10-yr austral summer convection-permitting simulation over the Maritime Continent region, as described in Vincent and Lane (2017) and available as an online dataset (Vincent and Lane 2016b). The simulations were produced using the WRF Model, version 3.5, and were forced at the boundaries by the ERA-Interim reanalysis (Dee et al. 2011), via an outer domain of 12-km horizontal grid length, and an inner nest with a 4-km horizontal grid length (Fig. 1). The simulations were run for a continuous 90-day period for each austral summer season, with nudging toward the ERA-Interim for wavelengths longer than $1000 \mathrm{~km}$ above the boundary layer on the outer domain so that realistic large-scale variability was maintained. Further details of the model setup can be found in Vincent and Lane (2017). The analysis in this paper focuses on the area around Sumatra, and a cross section through Sumatra, as indicated in Fig. 1. As well as the standard hourly model output, diabatic heating terms from the WSM6 microphysics scheme (Hong and Jeong-Ock 2006), the MYJ planetary boundary layer scheme (Mellor and Yamada 1982), and the net radiative heating from the RRTM longwave (Mlawer et al. 1997) and Goddard shortwave (Chou and Suarez 1994) radiation schemes were archived every 6 h.

\section{b. TRMM spectral latent heating and precipitation estimates}

Several efforts have been made to estimate convective and stratiform heating based on satellite-derived observations of surface precipitation, hydrometeor profiles, and other radar characteristics such as the existence of a brightband region. These methods are summarized in Tao et al. (2006) and may be grouped into methods based on lookup tables of profiles from cloud-resolving models and methods based on a more direct calculation. The SLH algorithm (Shige et al. 2004) builds on the convective stratiform heating (CSH) algorithm of Tao et al. (1993), where latent heating characteristics are determined from a lookup table based on precipitation characteristics of heating profiles from a convection-permitting model. The SLH algorithm differs importantly from the CSH algorithm in considering elevated stratiform rain as well as surface rain rates. In this work, we adopt the gridded, orbital output of the SLH algorithm, which is stored as the TRMM product 3G25 (TRMM Science Team 2011). Since the SLH product is calculated based on the TRMM Precipitation Radar only, it is available in limited satellite swaths. To avoid biasing our results toward times of day with more observations, we first bin the gridded swath data into four 6-h time bins and calculate the average of each bin, before averaging the four daily values to create a daily mean. For the analysis of the diurnal precipitation cycle in section 3a, the TRMM combined satellite 3-hourly gridded precipitation product 3B42 (Huffman et al. 2007; Tropical Rainfall Measuring Mission 2011) is also used.

\section{c. Rain-type classification}

In this study, a similar methodology to that used in Shige et al. (2004) is adopted for classification of rainfall types in the WRF Model simulations. In Shige et al. (2004), the classification was applied to two-dimensional convectionpermitting simulations in order to construct lookup tables for the TRMM SLH profiles that we compare with the simulated profiles in this study. Following Shige et al. (2004) we start by diagnosing any points with surface rain rates greater than $20 \mathrm{~mm} \mathrm{~h}^{-1}$ or with a rain rate greater than twice a background value (where the background is defined as the average of a 30 by 30 gridpoint box) as deep convective (DC), while all other points with surface precipitation were designated as deep stratiform (DS). In 


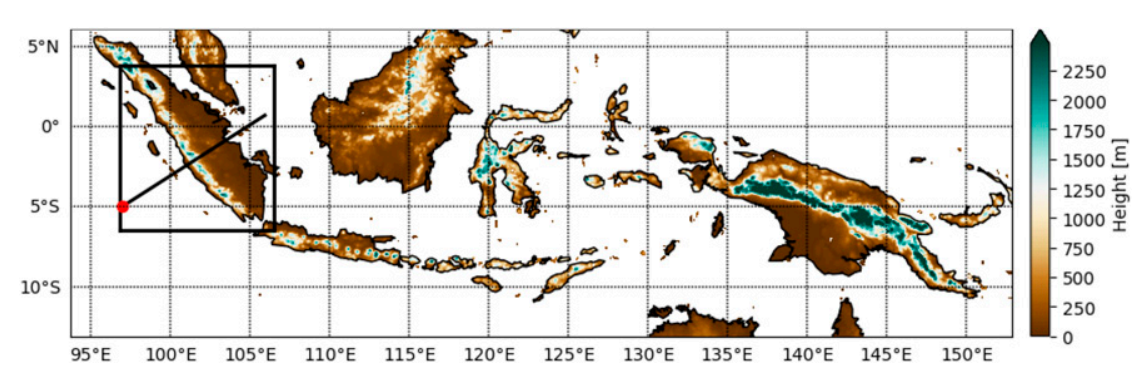

FIG. 1. Simulation domain. The focus area around Sumatra is indicated by the black box. The transect analyzed in section 3 is indicated by the thick black line, with $x=0$ at the red dot.

Shige et al. (2004), the background was defined as a 5 gridpoint box, but that model was two-dimensional with a horizontal resolution of $1 \mathrm{~km}$. In this study, where we use 3D simulations over real topography, it was found that using a smaller background area to define the background resulted in too few convective points being identifiedlikely due to the convective organization and correspondingly larger areas of precipitation-which resulted in grid points with an obvious deep heating profile being classified as shallow points.

Next, we followed the identification of elevated precipitating points in Shige et al. (2004) as being where there was nonzero positive rainwater mixing ratio anywhere in the column, but no surface rain. Of these elevated points, if the cloud water mixing ratio exceeded $0.5 \mathrm{~g} \mathrm{~kg}^{-1}$ or the updraft strength exceeded $3 \mathrm{~m} \mathrm{~s}^{-1}$ below the freezing level, they were designated as DC; otherwise, they were classified as elevated stratiform (ES). Finally, deep stratiform points were reassigned as shallow rain points if the cloud water mixing ratio was $>0.03 \mathrm{~g} \mathrm{~kg}^{-1}$ between 500 and $2000 \mathrm{~m}$. This threshold was determined by examination of cloud hydrometeor profiles. This differs from the procedure followed in Shige et al. (2004) where shallow points were diagnosed according to the precipitation top height. The shallow points are further classified as shallow convective (SC) if they are isolated or adjacent to deep convective points; the remaining shallow points are defined as shallow stratiform (SS).

\section{d. Simulated heating budget}

The simulated potential temperature budget may be written as

$$
\frac{D \theta}{D t}=\dot{\theta}_{M}+\dot{\theta}_{R}+\dot{\theta}_{T},
$$

where $\theta$ is the potential temperature; $D / D t$ is the material derivative operator; and $\dot{\theta}_{M}, \dot{\theta}_{R}$, and $\dot{\theta}_{T}$ are the potential temperature tendencies from the microphysics, radiation, and planetary boundary layer schemes, respectively, used in the WRF Model. Therefore, $\dot{\theta}_{M}$ represents the potential temperature tendency associated with all latent heating contributions from condensation, evaporation, freezing, melting, and precipitation. The term $\dot{\theta}_{T}$ represents the tendency imposed on potential temperature due to subgrid-scale turbulent mixing, and $\dot{\theta}_{R}$ represents the tendency due to the combined diabatic heating from net shortwave and net longwave radiation. For the purposes of this study, these tendencies are not decomposed further.

The potential temperature tendencies may be related to the apparent heating Q1, defined by Yanai et al. (1973), as

$$
\mathrm{Q} 1=c_{p}\left(\frac{P}{P_{0}}\right)^{R / c_{p}}\left(\frac{\partial \theta}{\partial t}+\mathbf{u}_{h} \cdot \nabla \theta+w \frac{\partial \theta}{\partial z}\right),
$$

or

$$
\mathrm{Q} 1=\frac{\partial s}{\partial t}+\mathbf{u}_{h} \cdot \nabla s+w \frac{\partial s}{\partial z},
$$

where $s=C_{p} T+g z$ is the dry static energy. It follows from Eqs. (1) and (2) that Q1 may also be expressed as the scaled sum of the diabatic heating terms:

$$
\mathrm{Q} 1=c_{p}\left(\frac{P}{P_{0}}\right)^{R / c_{p}}\left(\dot{\theta}_{M}+\dot{\theta}_{R}+\dot{\theta}_{T}\right) .
$$

In the analysis here, we present potential temperature tendencies as calculated in the WRF Model [except for in Figs. 11, 12, and 13 where profiles of potential temperature tendency are multiplied by $\left(P / P_{0}\right)^{R / c_{p}}$ for consistency with the TRMM estimates]. Since $\left(P / P_{0}\right)^{R / c_{p}}$ varies from close to unity at the surface to about 0.75 at $8000 \mathrm{~m}$ (the height of maximum heating), it does not make a significant qualitative difference to the results. (Note that we do not multiply by $c_{p}$, so we retain the units of $\mathrm{K} \mathrm{day}^{-1}$.)

The total derivative in Eq. (1) requires calculating the horizontal and vertical advection of potential temperature. Since the WRF Model uses a terrain-following 
coordinate system, the output was first interpolated to height levels with a constant spacing of $200 \mathrm{~m}$ before calculating the advection terms. The horizontal advection and vertical advection were calculated using the same respective fifth-order and third-order schemes used in the WRF Model. All the terms on the right-hand side of Eq. (1) and the advective part of $D \theta / D t$ represent instantaneous heating tendencies. However, because of the hourly model output, $\partial \theta / \partial t$ could only be calculated over a 2-h centered difference, and therefore represents the average heating over a 2 -h period. As demonstrated in section $3 \mathrm{~b}$, this smoothed representation of the heating causes a small discrepancy in the balancing of the budget, but does not qualitatively affect the spatially averaged results.

\section{Results}

\section{a. Comparison of diurnal precipitation cycle in WRF and TRMM $3 B 42$}

The simulations used in this study have previously been shown by Vincent and Lane (2017) to reproduce many physically realistic aspects of the variation of precipitation with time of day and MJO phase, but with some errors. For example, the simulated composite diurnal cycle for the eight MJO phases defined in Wheeler and Hendon (2004, hereafter WH04) is compared with that from the TRMM 3B42 V7 satellite precipitation estimates in Fig. 2 for the cross section through Sumatra indicated in Fig. 1. This analysis indicates a positive rainfall bias over the land and temporal offset of several hours in the timing of the peak of the diurnal precipitation cycle. This positive bias may be indicative of too much convective precipitation developing too early in the day, at the expense of stratiform rain forming in the evening and during the night. Despite the bias, the offshore propagation of precipitation and its variation with MJO phase is consistent between the simulations and observations, with a peak in precipitation over the land in phases 1 and 2, and the onset of more widespread precipitation over the sea in phases 2,3 , and 4 .

\section{b. Simulated heating budget around Sumatra}

The modeled potential temperature budget, averaged over the box around Sumatra for land and sea points (Fig. 1), is shown in Figs. 3 and 4 for MJO active days (WH04 phase 2) and MJO suppressed days (WH04 phase 7) for 0100 and 1300 LST. The profiles are averaged over the 10 -yr austral summer model dataset for days where the MJO is active, indicated by a WH04 amplitude greater than 1 . The budgets show extremely good agreement between $D \theta / D t$ (solid black) and the sum of the three diabatic heating terms (dashed black), indicating that all heating sources have been accounted for in the budget analysis. Deviation between the two terms above the tropopause is likely associated with the strong horizontal advection terms, which may contain errors due to the vertical regridding, and due to the smoothing of $\partial \theta / \partial t$ caused by the use of the 2 -h centered time difference, which would not capture transient features like high-frequency gravity waves.

At 1300 LST over the land, the heating budgets are dominated by the microphysics and vertical advection terms, with positive net heating. The strong contribution from surface heating is evident in the tendency from the PBL scheme, and there is weak radiative heating throughout troposphere. While the latent heating and vertical advection tendencies are smaller in the MJO suppressed case, the net heating is similar. Over the water at $1300 \mathrm{LST}$, the microphysics tendency is much smaller than over the land, but has the same sign as the vertical advection and radiative tendencies, leading to positive net heating.

At 0100 LST over the land, the microphysics tendencies are more top heavy, indicative of stratiform processes. As at 1300 LST, for both the MJO WH04 phase 2 (active) and phase 7 (suppressed), the vertical advection tendency and microphysics tendency almost balance, leading to a similar net heating. At 0100 LST over the water, there is considerably more latent heating in phase 2 (active) than phase 7 (suppressed). There is a negative potential temperature tendency because of melting at around $4.5 \mathrm{~km}$, compensated by vertical advection.

As discussed in section $2 \mathrm{~d}$, the $\dot{\theta}_{M}$ profiles are similar to profiles of Q1 as calculated by Yanai et al. (1973), Kodama et al. (2006), Shige et al. (2004), and others, since the contributions from radiation and turbulent vertical diffusion are comparatively small and the inclusion of the multiplier $\left(P / P_{0}\right)^{R / c_{p}}$ scales the profiles by only 0.75 at $8 \mathrm{~km}$, around the height of maximum heating. The results are also consistent with those of Lin et al. (2004), who showed that stratiform precipitation lagged convective precipitation by several days with the passage of the MJO. There is some agreement with the result of Kodama et al. (2006), who noted a peak in heating at around $4 \mathrm{~km}$ with a magnitude $6 \mathrm{Kday}^{-1}$ during the active MJO period over land around part of Sumatra (defined in their study at WH04 phases 2-3), despite expected cooling due to stratiform processes, which they mention may have been offset by heating from shallow convection. Their peak is of comparable magnitude but at a lower vertical level than the peak found in our study for the active phase, although not inconsistent with the peak found for convective processes alone as presented in section $3 \mathrm{~d}$. Their heating 
TRMM 3B42 V7
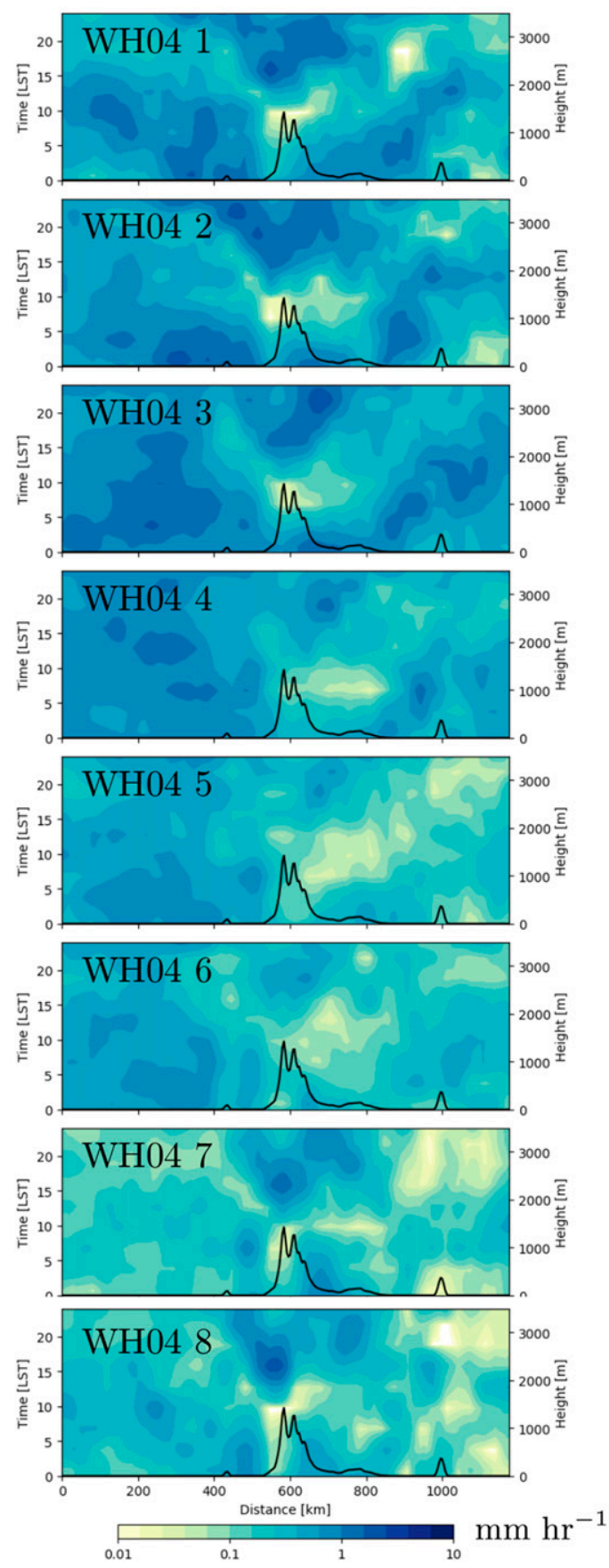
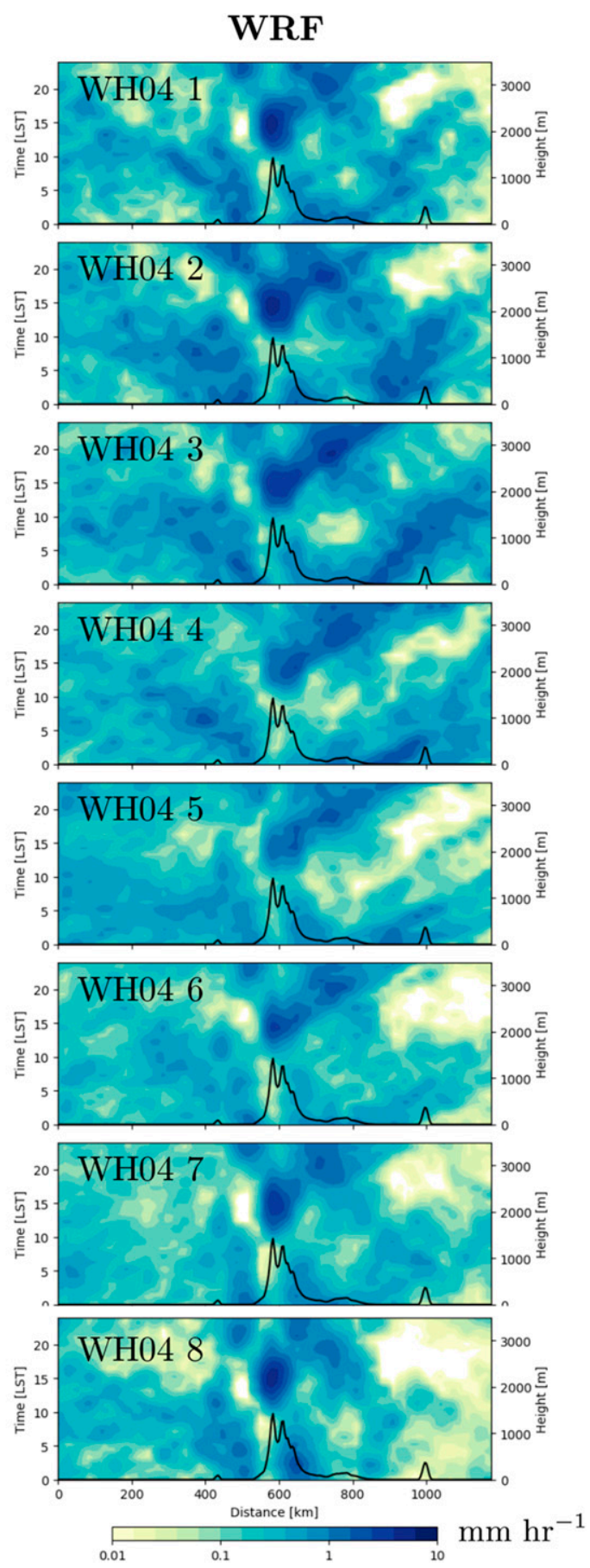

FIG. 2. Diurnally averaged Hovmöller diagrams of precipitation along the transect indicated in Fig. 1 for WH04 MJO index phases 1-8 with amplitude $>1$. Distance $=0$ corresponds to the red dot on the transect indicated in Fig. 1. The topography is shown as a black line with a secondary $y$ axis to indicate the location of the precipitation maxima relative to the coasts and the topographic peaks.

profile in the suppressed period (WH04 phases 7, 1, and 2, referred to as a "break" in their study) reached local minima at around 1 and $9 \mathrm{~km}$, with magnitudes of $1-2 \mathrm{~K} \mathrm{day}^{-1}$, which is more consistent with the results found here over water. The results are also partially consistent with heating profiles calculated during the Tropical Warm PoolInternational Cloud Experiment (TWP-ICE) by Xie et al. (2010) for the Darwin region, where a top-heavy 

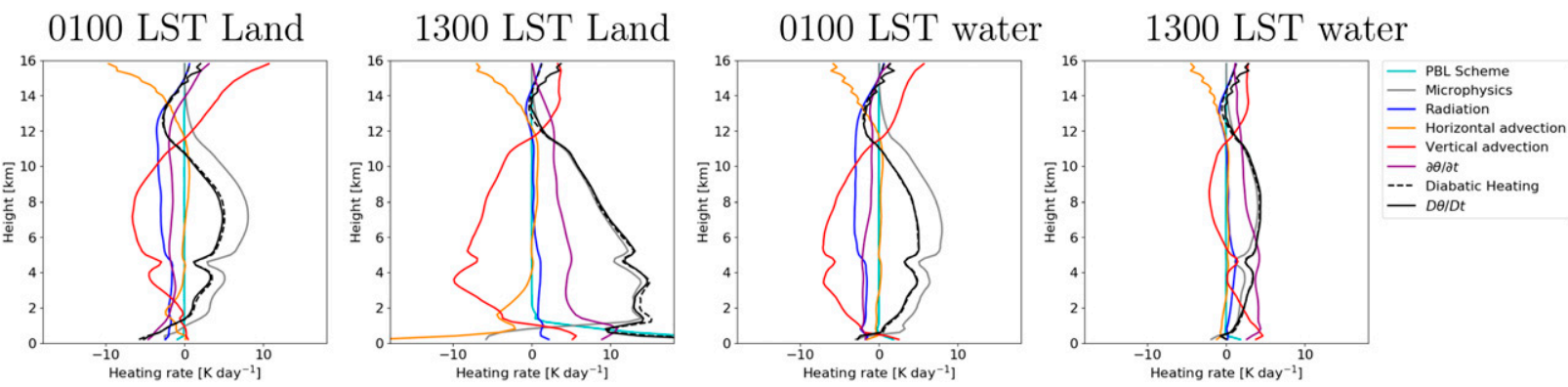

FIG. 3. Average heating profiles over the land and sea at 0100 and 1300 LST for WH04 phase 2 for the six budget terms. $D \theta / D t$ and the sum of the three diabatic heating terms in Eq. (1) are shown as the solid and dashed black lines, respectively.

profile during the active monsoon period (expected to be thermodynamically similar to the active MJO period) was shown to be closely balanced by vertical advection, while a more bottom-heavy profile of smaller magnitude was found in the suppressed monsoon phases. During the active phase, their Q1 profile reached a magnitude of around $16 \mathrm{~K} \mathrm{day}^{-1}$, which is larger than the values found in our study and those in Kodama et al. (2006).

The spatially averaged budget terms in Figs. 3 and 4 were also calculated on the cross sections through Sumatra shown in Fig. 1. In Figs. 5 and 6, each of the terms in Eq. (1) is contoured on distance-height axes at 0100 LST, averaged over all days with MJO amplitude $>1$ for WH04 phases 2 and 7 . We compare $\partial \theta / \partial t$ with $\dot{\theta}_{M}+\dot{\theta}_{R}+\dot{\theta}_{T}-\left(\mathbf{u}_{h} \cdot \nabla \theta+w \partial \theta / \partial z\right)$ (hereafter rhs) to show aspects of the heating relative to the topography. At this time of day, the radiation tendency is negative, and the precipitation has begun to migrate offshore, leading to positive microphysics and negative vertical advection tendencies on either side of Sumatra. It is evident that although the spatially averaged budgets in Figs. 3 and 4 balance well, there is a large amount of variability in the sum of the advection and diabatic terms that is not present in the relatively smoother $\partial \theta / \partial t$. This represents the difference in their calculation as $\partial \theta / \partial t$ is the 2-h average tendency and the rhs is the instantaneous tendency.

However, there is obvious consistency between regions of heating and cooling. The maximum radiative cooling takes place over the deepest clouds, and is reduced in WH04 phase 7 relative to phase 2 . There is also evidence of rays of cooling extending outward and upward from the coast in both $\partial \theta / \partial t$ and the rhs term, which are reminiscent of the gravity wave manifestation of the tropical sea breeze (Rotunno 1983). The cooling aloft implied by this propagation is important because of its potential to destabilize the environment far offshore, as proposed by Hassim et al. (2016). Note that the rays form angles of $0.3^{\circ}$ and $0.5^{\circ}$ on the southeast and northeast sides of the island, respectively, consistent with the value of $0.4^{\circ}$ predicted by the linear sea-breeze theory of Rotunno (1983) for a Brunt-Väisälä frequency of $0.01 \mathrm{~s}^{-1}$ and a latitude of $3^{\circ} \mathrm{S}$. Interestingly, these patterns of cooling are more obvious in the suppressed MJO phase.

Although the rays of cooling are evident extending upward and outward from the coast in the $\partial \theta / \partial t$ term, this feature is not directly evident in any one of the individual budget terms. If these rays are indeed an echo of the gravity wave manifestation of the tropical sea breeze, then they should be present in the advection terms, since linear gravity waves are adiabatic. To confirm this, we plot the difference between the advection and microphysics terms, $\mathbf{u}_{h} \cdot \nabla \theta+w(\partial \theta / \partial z)-\dot{\theta}_{M}$, in Fig. 7, which reveals characteristic rays of cooling at 0100 LST and, to a lesser extent, corresponding heating at 1300 LST. This implies that the gravity wave signal is obscured by the strong updrafts and downdrafts relating to the convection,
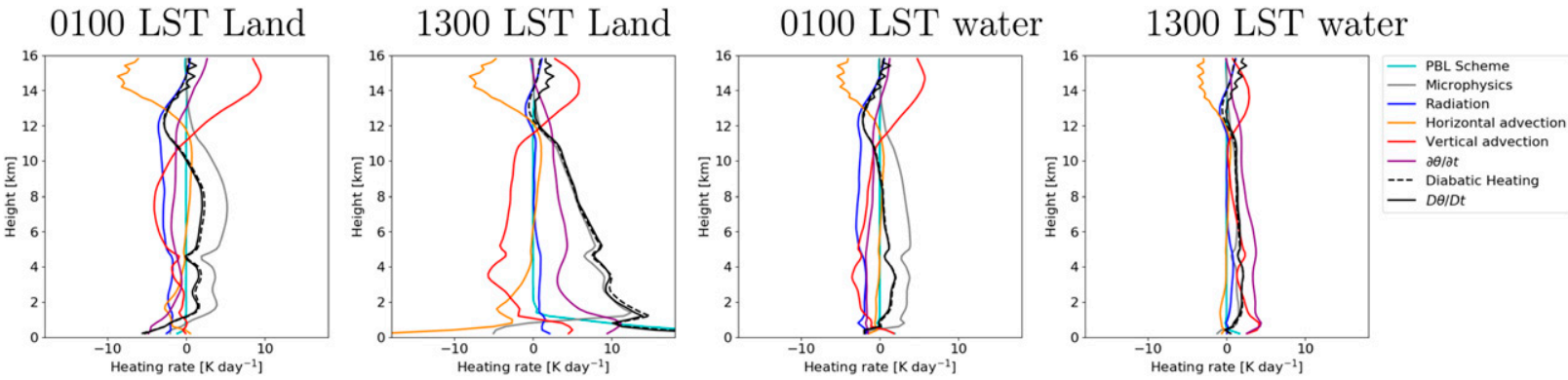

FIG. 4. As in Fig. 3, but for WH04 phase 7. 

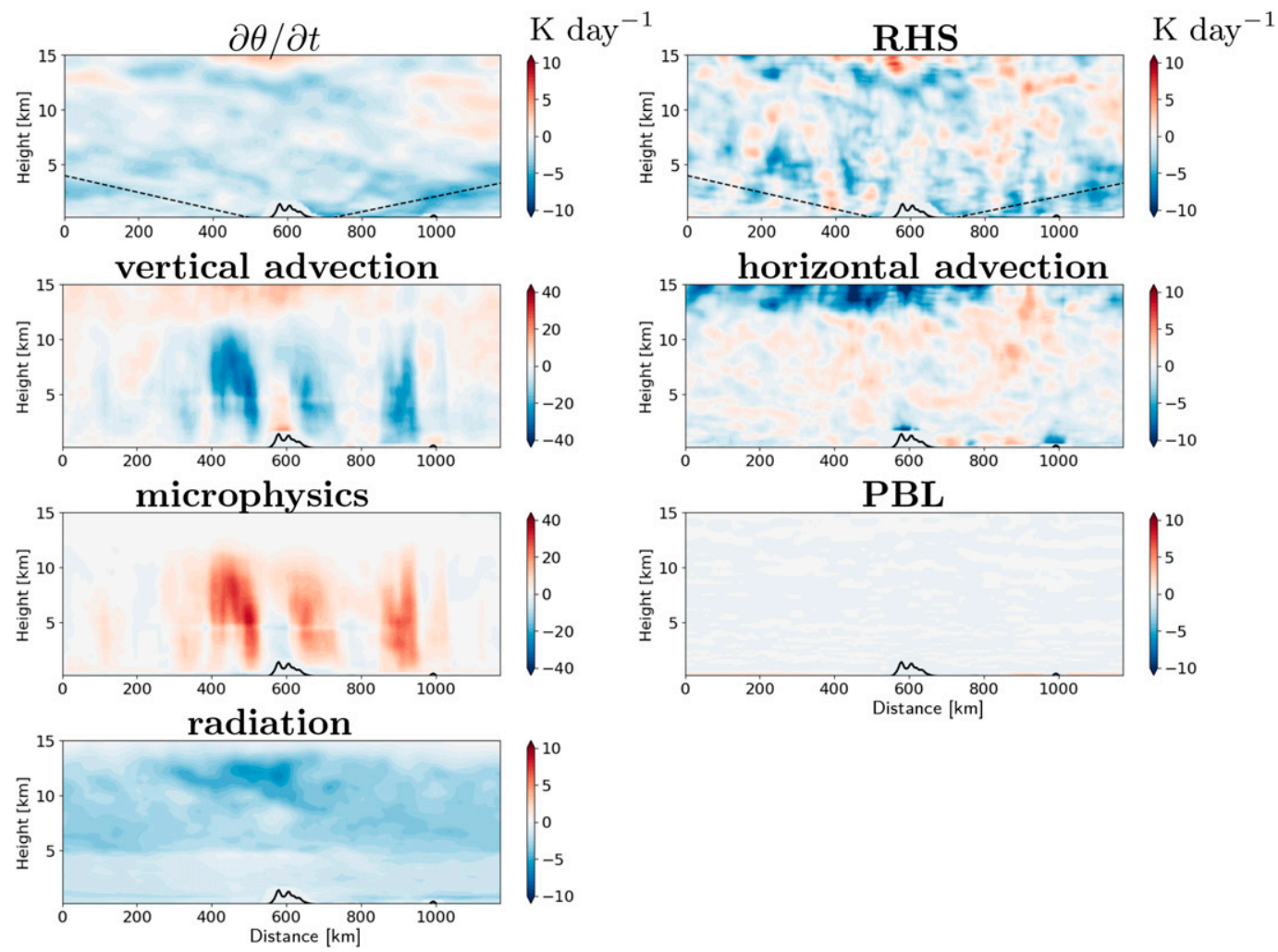

FIG. 5. Heating budget terms along the transect through Sumatra for WH04 phase 2 at 0100 LST. The solid black line indicates the height of the topography. Dashed black lines on the $\partial \theta / \partial t$ and rhs plots indicate the approximate location of the propagating wave disturbance.

but is nonetheless present once this effect is removed. The analysis is repeated for MJO WH04 phases 2 and 7, where it is shown to be remarkably invariant considering the strong difference in the amount of convection and the different amounts of precipitation (shown as gray contours). This is consistent with Vincent and Lane (2016a), who showed that the potential temperature anomalies associated with the tropical sea breeze off the northeast coast of New Guinea changed little with the passage of the MJO, despite strong modulation of precipitation amounts, suggesting that precipitation is modulated more by moisture availability than sea-breeze dynamics. Note that the daytime heating follows a steeper slope than the nighttime cooling, and appears to have its origin around $1000 \mathrm{~m}$ above the coast, particularly on the northeast side of the island. This is likely due to the elevated heating arising from the deep convection over the land during the day.

\section{c. Conditional microphysics heating by rain type}

In this section, we decompose the microphysics heating term into the five rainfall categories described in section $2 \mathrm{c}$, averaged on the same cross section through Sumatra that has been used previously, for WH04 phases 2, 4, and 7 (Figs. 8, 9, and 10). Phases 2 and 4 represent the early and late stages of the MJO active period, respectively, while phase 7 represents the suppressed period. We see that the rainfall classification (for which no a priori information about latent heating is used) follows expected patterns, with strong updrafts of heating throughout the troposphere for the DC category, and stratiform rain with heating aloft and cooling below for the DS category. The shallow convective category includes weaker and shallower updrafts, consistent with the classification. The shallow stratiform category is less clear and appears similar to the shallow convective category, but this is not unexpected because shallow clouds are a subgrid process in a 4-km grid-length convection-permitting model. This means that the regions identified by the algorithm as shallow stratiform or shallow convective will likely not be physically realistic. Note that the magnitude of these terms is small compared with the deep convective term.

Although there is no unique way of decomposing the microphysics heating into rainfall types, several interesting patterns can be deduced from Figs. 8-10. First, there is more stratiform heating over the water in WH04 phase 4 than WH04 phase 2 . This means that in WH04 phase 2, a gap emerges over the land at around midday, which allows strong radiational heating and 

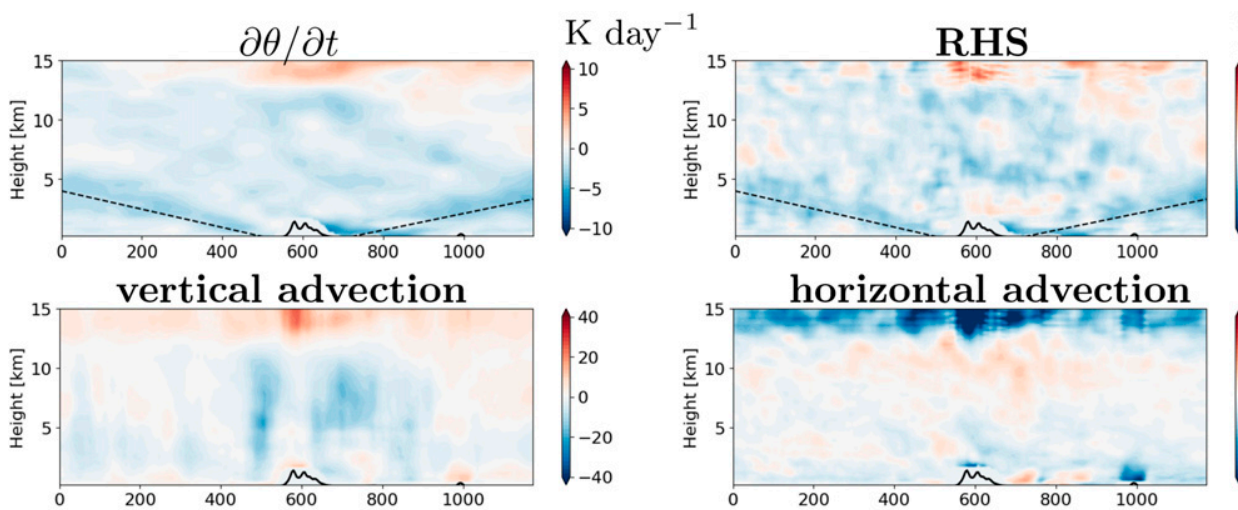

$\mathrm{K}_{\text {day }}{ }^{-1}$
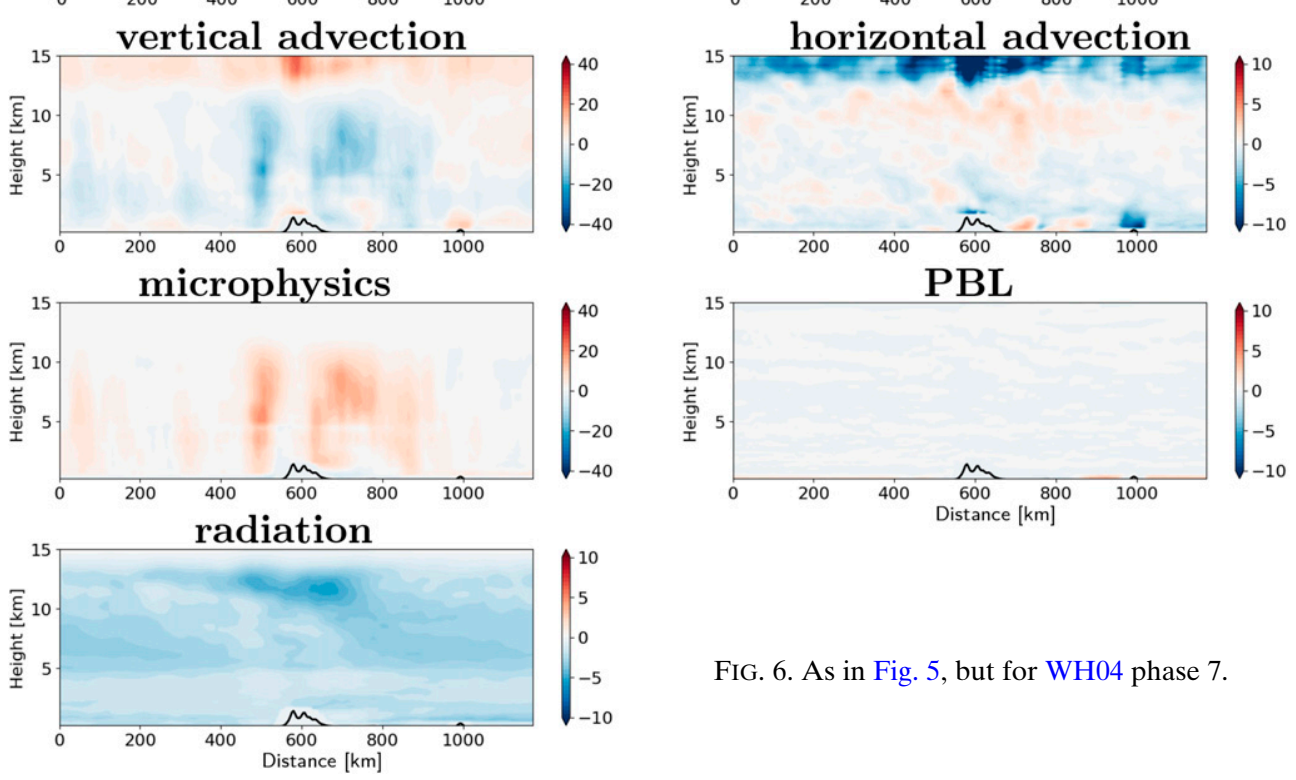

FIG. 6. As in Fig. 5, but for WH04 phase 7.

strong convective development during the afternoon. In contrast, in WH04 phase 4, the stratiform cloud persists throughout the day, no such gap emerges over the land, and a weaker convective core over the land develops. In $\mathrm{WH} 04$ phase 7 , there is little stratiform heating, and only a few weak convective cores over the land. This is consistent with recent results that have shown the diurnal precipitation reaching a maximum over the land ahead of the main MJO envelope (Peatman et al. 2014; Vincent and Lane 2017; Birch et al. 2016).

\section{d. Average potential temperature tendency profiles by MJO category}

The total area-averaged latent heating from microphysics for the five different rainfall categories discussed
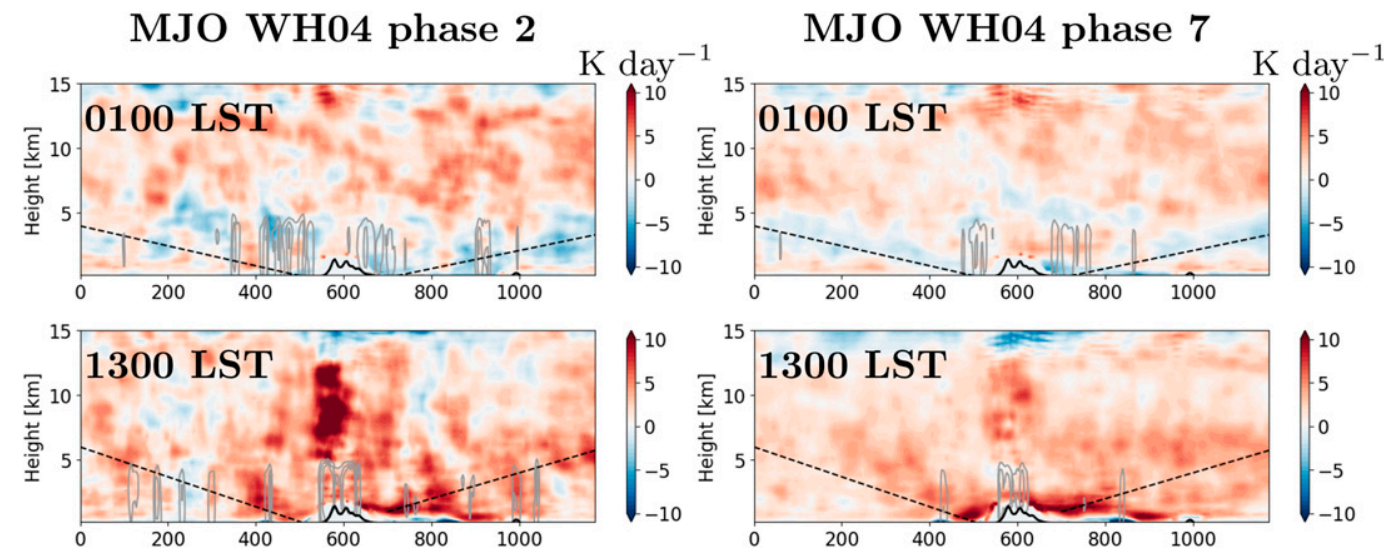

FIG. 7. Potential temperature tendency from horizontal and vertical advection minus microphysics. Contours of rainwater mixing ratio levels $0.05,0.1$, and $0.15 \mathrm{~g} \mathrm{~kg}^{-1}$ are shown in gray. The solid black line indicates the height of the topography. Dashed black lines indicate the approximate location of the propagating wave disturbance. 

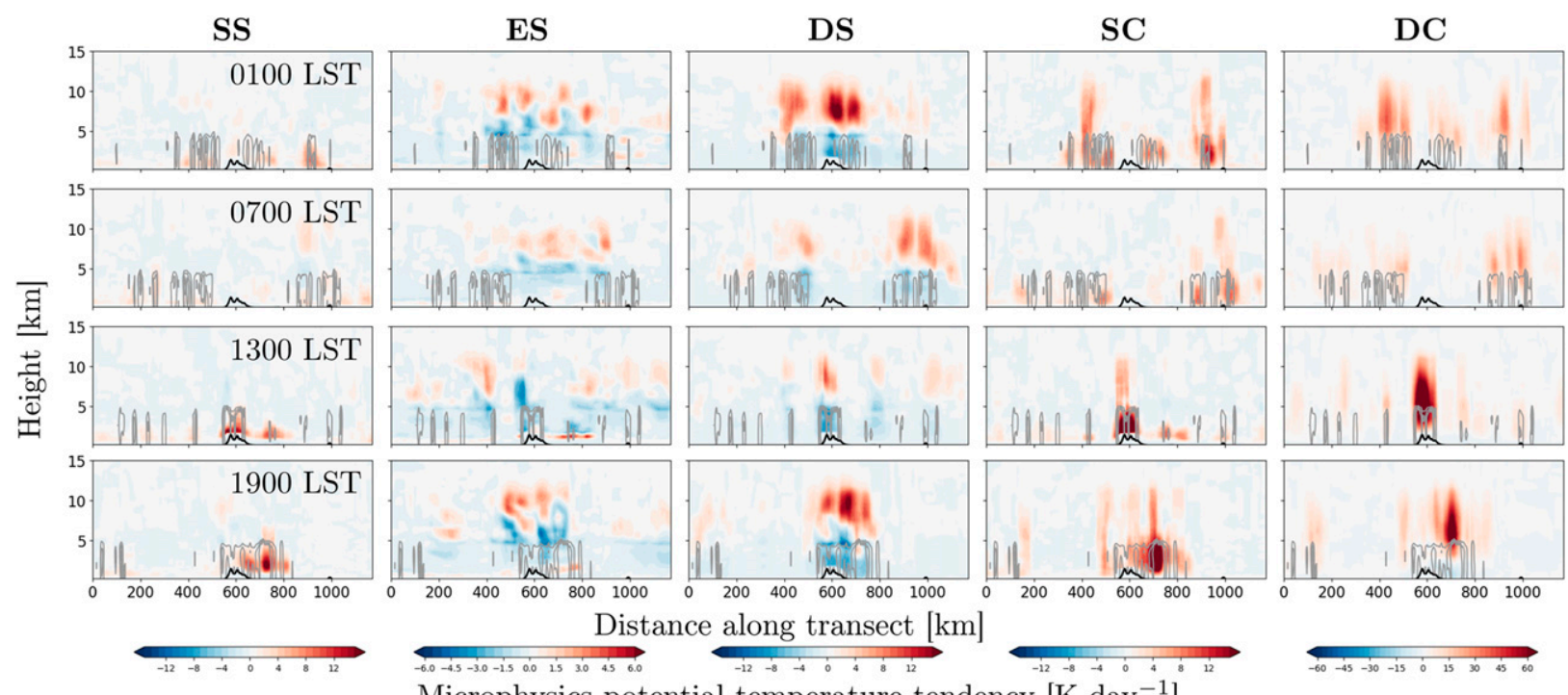

Distance along transect $[\mathrm{km}]$

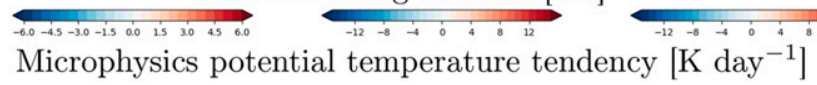

FIG. 8. Simulated contribution to latent heating from precipitation classes shallow stratiform (SS), elevated stratiform (ES), deep stratiform (DS), shallow convective (SC), and deep convective (DC) for WH04 phase 2. Rainwater mixing ratio contours of $0.05,0.1$, and $0.15 \mathrm{~g} \mathrm{~kg}^{-1}$ are indicated in gray. The solid black line indicates the height of the topography.

in section 2 is shown in Fig. 11 for the eight MJO WH04 phases. The heating profiles for convective and stratiform rainfall follow the expected forms, with deep heating throughout the troposphere in convective precipitation and heating above about $6000 \mathrm{~m}$ with cooling below for stratiform precipitation. Note that the heating profile was not used in the classification of rainfall types, so these results also serve as a consistency check on the method of convective-stratiform separation. For the elevated stratiform rain, the latent heating becomes negligible below about $2000 \mathrm{~m}$.
The shallow convective and shallow stratiform heating curves are similar to one another, which is expected given that the distinction between these two categories depends only on whether grid points that have been identified as shallow are isolated or adjacent to deep convective grid points, or whether they are adjacent to deep stratiform grid points. We do, however, note a slightly deeper layer of heating in the shallow convective case. Shallow precipitation is likely representative of trade cumulus, which was shown to have a frequency of occurrence of $10 \%-20 \%$ around Sumatra in Tan et al. (2013). Medeiros et al. (2010)
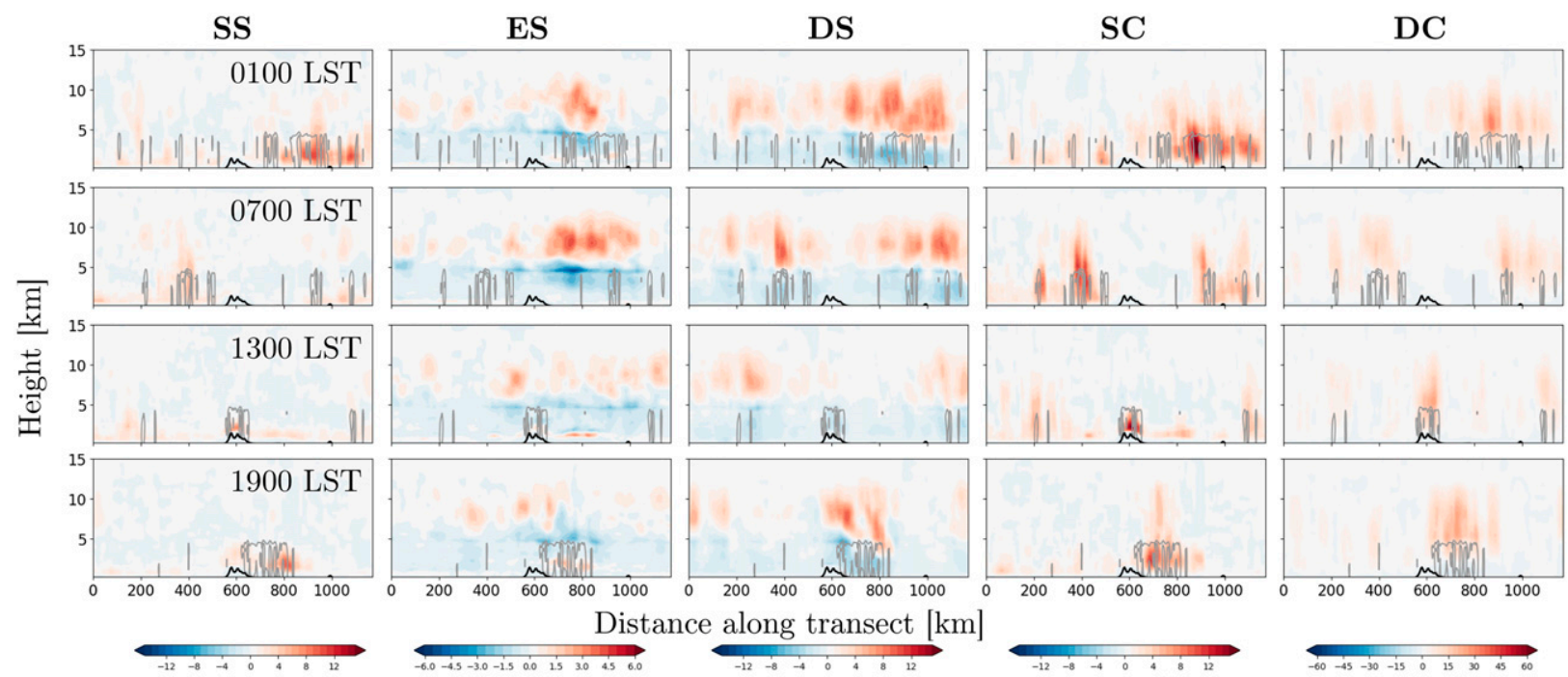

Distance along transect $[\mathrm{km}]$
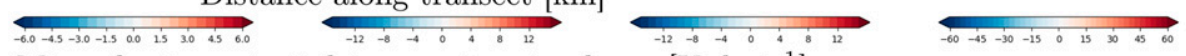

Microphysics potential temperature tendency $\left[\mathrm{K}^{-1}\right.$ day $\left.^{-1}\right]$

FIG. 9. As in Fig. 8, but for WH04 phase 4. 

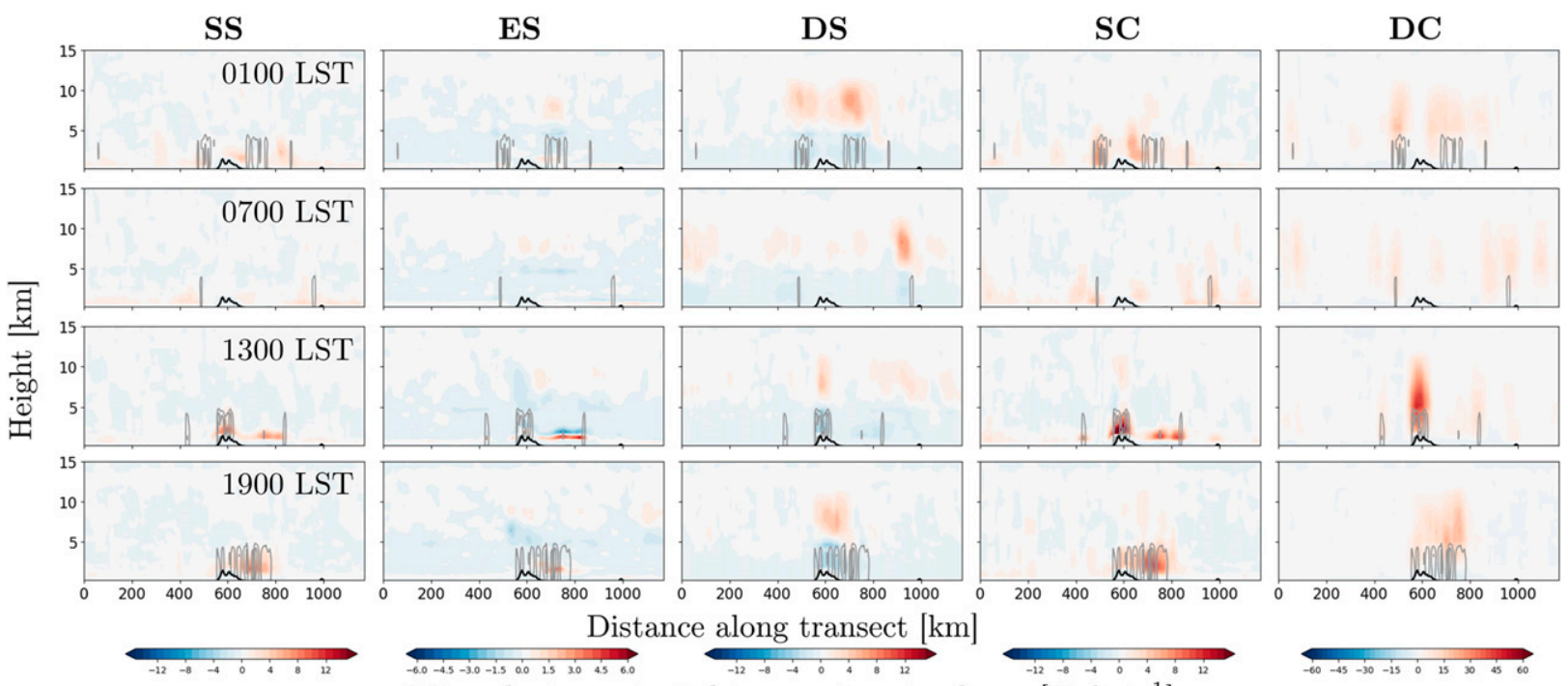

Distance along transect $[\mathrm{km}]$
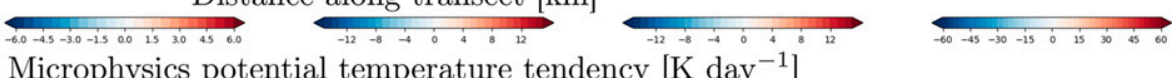

Microphysics potential temperature tendency $\left[\mathrm{K}\right.$ day $\left.^{-1}\right]$

FIG. 10. As in Fig. 8, but for WH04 phase 7.

also found a local maximum in the frequency of cloud-top height at around $2 \mathrm{~km}$ over tropical oceans from the analysis of CALIPSO retrievals, which was attributed to shallow convection, and Jakob and Schumacher (2008) found a frequency of occurrence of around $20 \%$ over the sea to the northeast of New Guinea. However, as mentioned earlier, shallow cumulus convection is unresolved in a simulation with a horizontal grid spacing of $4 \mathrm{~km}$, which means that what appears as low cloud is unlikely to mimic realistic physical processes.

We choose to retain the two categories of shallow stratiform and shallow convection, since despite their similar heating profiles, Figs. $8-10$ suggest that there is actually some physical distinction between the two categories. For example, heating from shallow convection is mostly collocated with distinct updrafts, mostly offshore, while shallow stratiform appears predominantly as a shallow layer of heating concentrated to the northeast of Sumatra.

\section{e. Comparison to observed latent heating profiles}

The WRF latent heating profiles were compared with the profiles from the TRMM SLH product (Fig. 12). Because the SLH product comes from the TRMM Precipitation Radar, it has limited temporal and spatial coverage. As discussed in section 2, an even temporal distribution through the day was achieved by first binning to 6-hourly time bins, before calculating a daily average. The full available TRMM data were used, covering the time period 1998-2015-this longer period was chosen to increase the amount of data available, and is reasonable since we conditionally average all the data by MJO category. For each $50 \mathrm{~km} \times 50 \mathrm{~km}$ grid point, there were between 5 and 20 values in each MJO category at each time of day (with WH04 amplitude $>1$ ), which are then spatially averaged over land and sea areas. The limited amount of data used should therefore be taken into account when drawing conclusions from this comparison.

Further to these issues about the limited sampling of the TRMM dataset, we see that there are notable differences in the shapes of the heating curves. The WRF convective heating extends deeper than the TRMM convective heating, while the height of the peak in stratiform heating seems relatively consistent. This is consistent with prior studies that show convectionpermitting models to produce convective cases that are too deep (e.g., Caine et al. 2013). The shallow heating, which is distributed between shallow convective and shallow stratiform categories, has an obvious impact on the total simulated stratiform heating profile. Arguably, this shallow heating could have been placed into the convective category.

Despite these limitations, there are some useful patterns in the WRF Model and TRMM results. In both cases, the stratiform heating plays a greater role in phase 3 than phase 2, while the maximum convective heating occurs in phases 2 and 3. Also, in both the WRF Model and TRMM estimates, the stratiform heating is still close to its maximum value in phase 4 , while by phase 4 the convective heating has decreased significantly. This indicates a lag between the maximum convective and maximum stratiform precipitation, consistent with Lin et al. (2004). 

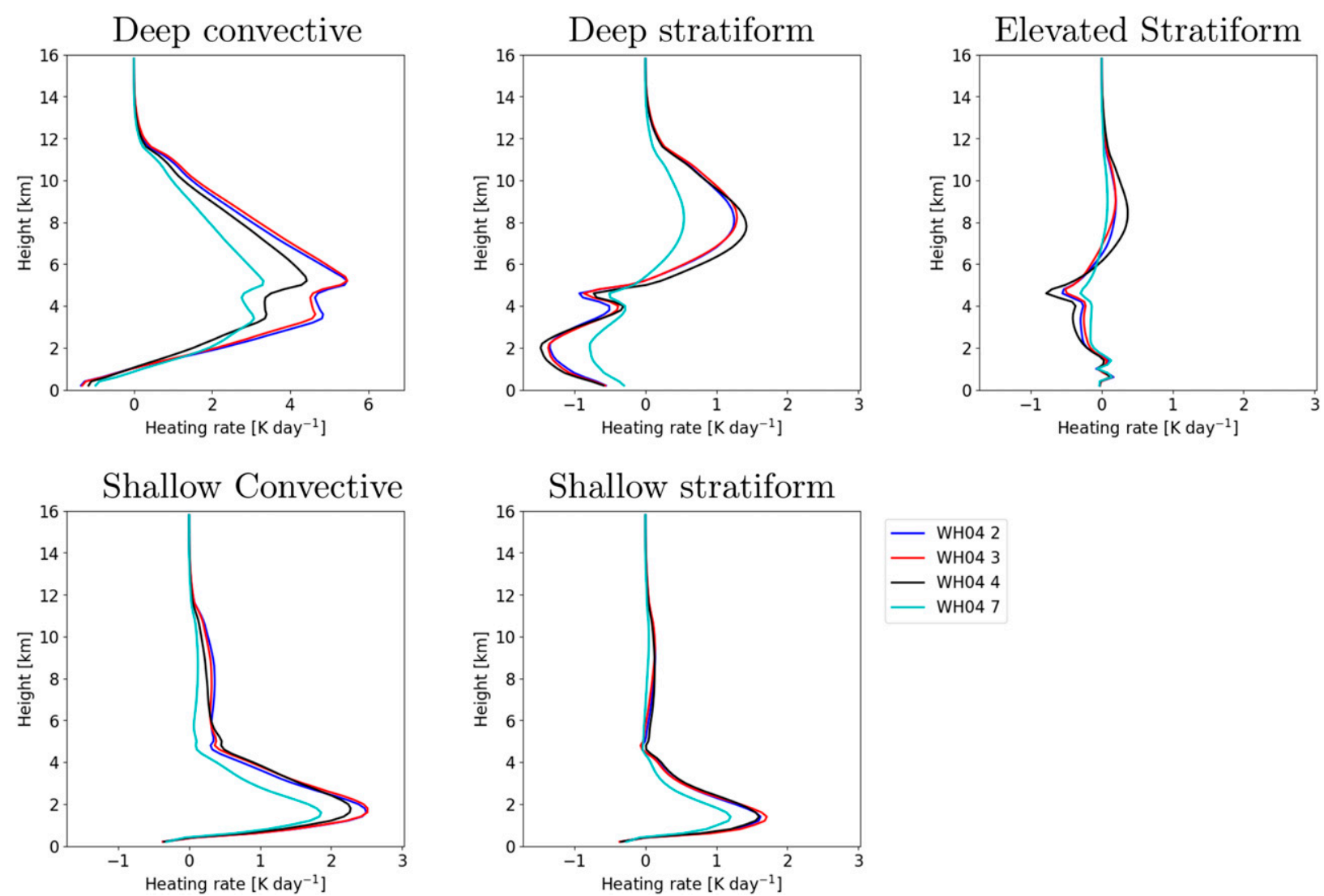

FIG. 11. Simulated contribution to latent heating $\left[\dot{\theta}_{M}\left(P / P_{0}\right)^{R / c_{p}}\right]$ from five precipitation categories for MJO WH04 phases $2,3,4$, and 7.

Jakob and Schumacher (2008) found that stratocumulus was almost nonexistent in the region around Sumatra. This suggests the low-altitude stratiform heating found in the rainfall decomposition presented here is unlikely to be realistic, as also noted by Ahmed et al. (2016). If all the stratiform low-altitude heating is considered to be the model representation of subgrid-scale trade cumulus, then it should be included in the convective category. In Fig. 13, this stratiform low-altitude heating is included in the convective category and compared with the same TRMM profiles shown in Fig. 12. This shows that the stratiform heating profile takes on a much more realistic shape, and is more similar to the TRMM profile. However, there is an obvious "bulge" in the shape of the convective heating profile near the surface, suggesting that there may be too much low cloud in the simulations. The sensitivity of this inflated low-level heating to model resolution, choice of microphysics and boundary layer physics, and the use of a shallow cumulus parameterization are topics for future study. The basic trends in the profiles are insensitive to this reclassification, which shows that convective heating leads stratiform heating in both simulated and TRMM data, and that the WRF Model appears to produce too much convective heating and insufficient stratiform heating.

\section{Discussion}

It was possible to calculate a fully balanced, gridded heating budget for tropical convection over Sumatra as simulated by the WRF Model, using stored tendencies from the model physics and advective tendencies calculated offline. The analysis demonstrated that the microphysics tendencies, which arise from phase changes between gaseous, liquid, and frozen water, are in most cases closely balanced by the vertical advection tendencies, particularly when in the presence of strong convection. When the convection is weak, radiation plays a greater relative role.

We showed that the total microphysics heating was from a combination of stratiform and convective processes, which contribute to the total heating profile through upperlevel heating and midlevel cooling in the former case, and heating throughout the troposphere in the latter case. While the precise delineation between convective and stratiform processes is subject to numerous uncertainties, it is clear that the relative contribution of rainfall types controls the type of heating that is experienced.

A greater contribution to both the microphysics and radiative terms was found in the MJO active phases than in the MJO inactive phases. This was expected, because of 

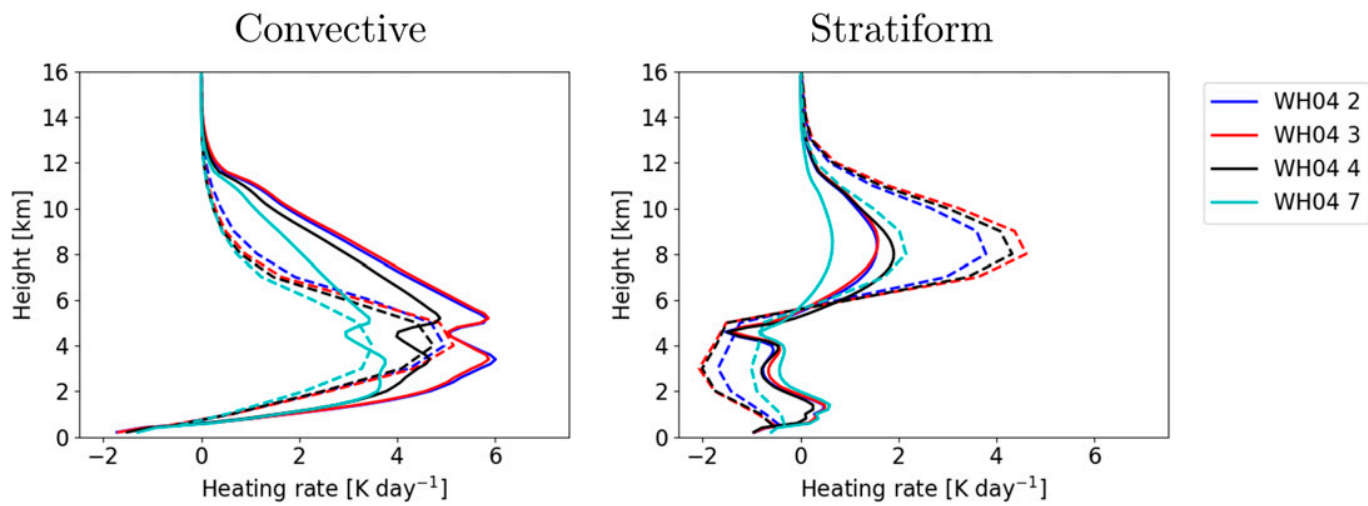

FIG. 12. Simulated and observed contribution to latent heating $\left[\dot{\theta}_{M}\left(P / P_{0}\right)^{R / c_{p}}\right]$ from convective and stratiform precipitation types for MJO WH04 phases 2, 3, 4, and 7. Solid lines are from simulations and dashed lines are from TRMM.

the increase in cloudiness and convection associated with the MJO. However, it was apparent that in the absence of deep convection offshore, the rays of heating and cooling associated with the gravity wave manifestation of the tropical sea breeze dominated the net local potential temperature tendency. Analysis of transects of microphysics heating through Sumatra shows that convective processes reach a maximum during the first part of the MJO active period, while stratiform cloud processes reach a maximum 1-2 WH04 phases later. This is seen in heating profiles from both WRF Model simulations and estimates from the TRMM satellite. On transects through Sumatra, an increase in stratiform heating and a decrease in convective heating is seen between phases 2 and 4 . In particular, in phase 2, a gap in stratiform cloud processes over the land emerges during the morning, allowing strong convective development during the afternoon. In contrast, in phase 4, stratiform processes persist over the land, contributing to reduced convective development.
Comparison of simulated heating profiles from convective and stratiform rain with analogous profiles derived from the TRMM Precipitation Radar suggested that the WRF Model is producing too much convective precipitation and not enough stratiform precipitation, an observation that is validated by inspection of rainfall maps or Hovmöller diagrams, that show the WRF rainfall concentrated over smaller, heavier areas than the more widespread rainfall from the TRMM Precipitation Radar. Separately analyzing the convective and stratiform parts of the latent heating allows us to attribute model errors to specific processes. In future studies, this provides a more rigorous approach for comparing the behavior of different modeling frameworks and potential model improvements than validating surface rainfall alone. This is especially relevant in the Maritime Continent, where there are important model errors in the timing of the diurnal precipitation cycle, and in the mesoscale feedbacks with associated intraseasonal-scale variability.
Convective

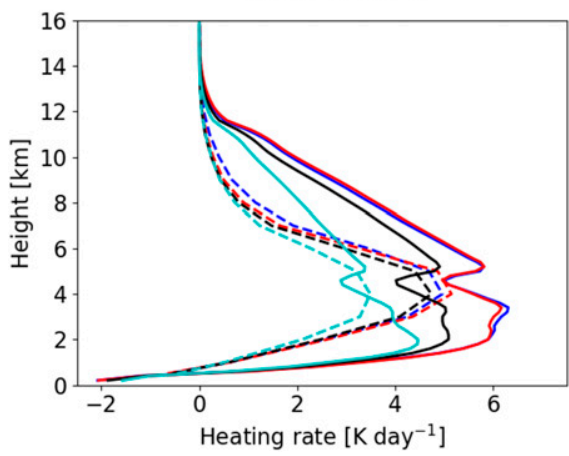

Stratiform

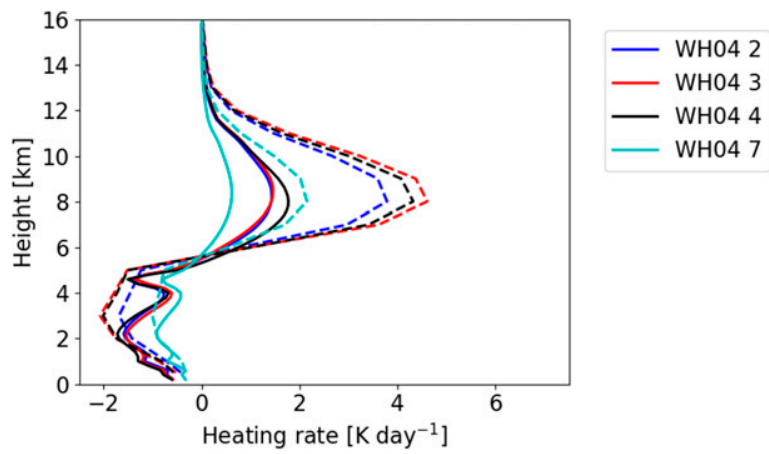

FIG. 13. Simulated and observed contribution to latent heating $\left[\dot{\theta}_{M}\left(P / P_{0}\right)^{R / c_{p}}\right]$ from convective and stratiform precipitation types for MJO WH04 phases 2, 3, 4, and 7, with all low clouds included in the convective category. Solid lines are from simulations and dashed lines are from TRMM. 
Rays of heating during the day and cooling during the night were also detected in the local potential temperature tendency. These rays were difficult to discern in any individual term in the heating budget, but are apparent in $\partial \theta / \partial t$ and the residual of the advection and microphysics terms. They can, therefore, be interpreted as the part of the local tendency that is associated with adiabatic motion, and are likely a signature of gravity waves extending outward and upward from the coast.

The difficulty in classifying the shallow clouds highlights an important limitation of numerical weather and climate models, even with the convection-permitting grid length $(4 \mathrm{~km})$ used here. At this resolution, shallow clouds are underresolved, and the apparent low clouds produced by the model are unlikely to be physically realistic. Unphysical low clouds in the WRF Model were also noted by Ahmed et al. (2016) in their analysis of heating from simulations with horizontal grid spacing of $500 \mathrm{~m}$ and $2 \mathrm{~km}$. They also argued that the low clouds were an artifact of subgrid-scale processes, and avoided contaminating their stratiform heating profiles with the these clouds by neglecting any cloud clusters smaller than $4 \mathrm{~km}^{2}$ and treating clusters smaller than $200 \mathrm{~km}^{2}$ as convective. Interestingly, their model ran with a different microphysics scheme, indicating that this issue is not limited to the WSM6 scheme used here. The representation of low clouds may in fact be key to accurately simulating the MJO, with several studies pointing to the role of shallow convection ahead of the MJO in preconditioning the atmosphere (Cao and Zhang 2017; Lin et al. 2004; Klingaman et al. 2015). This is not what is seen in the shallow profiles presented here, with the magnitudes of both shallow convective and stratiform rain following a similar ordering to deep convection, but this may be less important in a regional model where large-scale information is regularly updated through the boundaries and from the nudging of the longer wavelengths in the outer domain.

It is worth noting that in attributing latent heating to rainfall types, only the microphysical processes occurring in the presence of surface or elevated precipitation are accounted for, yet these clouds accounted for most of the latent heating from the microphysics scheme. This makes the strategy of diagnosing rainfall types a useful tool for validating diabatic heating in a hierarchy of models. For example, the heating in a convection-permitting model could be treated as an approximate representation of the true heating for validation and development of climatescale models with parameterized convection. Conversely, comparing the heating terms from a convection-permitting model such as the one used in this study with large eddy simulation models (where shallow processes are more completely resolved) or with model versions with a shallow convection parameterization, could yield critical results about the diurnal evolution of convection over the steep islands of the Maritime Continent and surrounding ocean.

\section{Conclusions}

The balanced potential temperature budget from 10 years of austral summer simulations over the whole Maritime Continent from the WRF Model allowed a quantification of the diurnal and intraseasonal-scale variation in diabatic heating. Decomposition of the heating into the contributions from convective, stratiform, and shallow processes showed a different sequence of heating with the MJO for the different rainfall types, with convective processes reaching a maximum one to two phases ahead of stratiform processes.

Our analysis also identifies the existence of rays of heating extending outward and upward from the coast as a signature of gravity waves, although the precise role of the cooling aloft in modulating precipitation offshore remains unclear because of its small magnitude relative to that associated with diabatic heating. We also clearly identified that these rays of heating and cooling exist even when there is almost no precipitation offshore, suggesting that any impact of these waves is limited to when other conditions (such as moisture availability) are favorable.

Directly analyzing heating from precipitating clouds presents a more rigorous approach to understanding the interscale feedbacks than looking at surface rain rate alone. Atmospheric moistening, as the counterpart of diabatic heating, is also key to understanding these processes but beyond the scope of the present study. Considering convective and stratiform processes separately is an important tool for diagnosing long-standing errors in diurnal and intraseasonal precipitation variability in the tropics. Applying a similar analysis on a higher-resolution model with explicitly resolved shallow processes will reveal much about what is missing from a model where these processes occur at the subgrid scales. This is a topic of future research.

Finally, our comparison between the WRF Model and TRMM, despite its limitations, identified deficiencies in the model representation of stratiform processes, and how those processes vary with the passage of the MJO. Correcting these deficiencies should continue to be a high priority as they likely affect convection-permitting model representation of rainfall across all scales. This is a theme of ongoing research.

Acknowledgments. This work was funded by the Australian Research Council's Centre of Excellence Program (CE170100023). The WRF Model simulations for this research were undertaken on the NCI National Computing Facility in Canberra, Australia, which is 
supported by the Australian Commonwealth Government. Thank you to Shoichi Shige for advice about TRMM SLH products, Bethan White for advice about aspects of the WRF simulations, and Gretchen Mullundore for helpful discussions about the manuscript. Thanks also to Walter Hannah and two anonymous reviewers for their comments that helped improved the manuscript.

\section{REFERENCES}

Ahmed, F., C. Schumacher, Z. Feng, and S. Hagos, 2016: A retrieval of tropical latent heating using the 3D structure of precipitation features. J. Appl. Meteor. Climatol., 55, 19651982, https://doi.org/10.1175/JAMC-D-15-0038.1.

Birch, C., S. Webster, S. C. Peatman, D. Parker, A. Matthews, Y. Li, and M. Hassim, 2016: Scale interactions between the MJO and the western Maritime Continent. J. Climate, 29, 2471-2492, https://doi.org/10.1175/JCLI-D-15-0557.1.

Caine, S., T. P. Lane, P. T. May, C. Jakob, S. T. Siems, M. J. Manton, and J. Pinto, 2013: Statistical assessment of tropical convection-permitting model simulations using a cell-tracking algorithm. Mon. Wea. Rev., 141, 557-581, https://doi.org/ 10.1175/MWR-D-11-00274.1.

Cao, G., and G. J. Zhang, 2017: Role of vertical structure of convective heating in MJO simulation in NCAR CAM5.3. J. Climate, 30, 7423-7439, https://doi.org/10.1175/JCLI-D-16-0913.1.

Chou, M.-D., and M. J. Suarez, 1994: An efficient thermal infrared radiation parameterization for use in general circulation models. NASA Tech. Memo. 104606, Vol. 3, 102 pp.

Dee, D. P., and Coauthors, 2011: The ERA-Interim reanalysis: Configuration and performance of the data assimilation system. Quart. J. Roy. Meteor. Soc., 137, 553-597, https://doi.org/ 10.1002/qj.828.

Fujita, M., K. Yoneyama, S. Mori, T. Nasuno, and M. Satoh, 2011: Diurnal convection peaks over the eastern Indian Ocean off Sumatra during different MJO phases. J. Meteor. Soc. Japan, 89A, 317-330, https://doi.org/10.2151/jmsj.2011-A22.

Hassim, M. E. E., T. P. Lane, and W. Grabowski, 2016: The diurnal cycle of rainfall over New Guinea in large-domain, convectionpermitting WRF simulations. Atmos. Chem. Phys., 16, 161-175, https://doi.org/10.5194/acp-16-161-2016.

Hong, S.-Y., and J. L. Jeong-Ock, 2006: The WRF Single-Moment 6-Class Microphysics Scheme (WSM6). J. Korean Meteor. Soc., 42, 129-151.

Houze, R. A., Jr., 2004: Mesoscale convective systems. Rev. Geophys., 42, RG4003, https://doi.org/10.1029/2004RG000150.

— S. Geotis, F. D. Marks Jr., and A. West, 1981: Winter monsoon convection in the vicinity of North Borneo. Part I: Structure and time variation of the clouds and precipitation. Mon. Wea. Rev. 109, 1595-1614, https://doi.org/10.1175/1520-0493(1981)109<1595: WMCITV $>2.0 . \mathrm{CO} ; 2$.

Huffman, G. J., and Coauthors, 2007: The TRMM Multisatellite Precipitation Analysis (TMPA): Quasi-global, multiyear, combinedsensor precipitation estimates at fine scales. J. Hydrometeor., $\mathbf{8}$, 38-55, https://doi.org/10.1175/JHM560.1.

Jakob, C., and C. Schumacher, 2008: Precipitation and latent heating characteristics of the major tropical western Pacific cloud regimes. J. Climate, 21, 4348-4364, https://doi.org/ 10.1175/2008JCLI2122.1.

Klingaman, N. P., and Coauthors, 2015: Vertical structure and physical processes of the Madden-Julian oscillation: Linking hindcast fidelity to simulated diabatic heating and moistening. J. Geophys. Res. Atmos., 120, 4690-4717, https://doi.org/10.1002/ 2014JD022374.

Kodama, Y.-M., M. Tokuda, and F. Murata, 2006: Convective activity over the Indonesian Maritime Continent during CPEA-I as evaluated by lightning activity and Q1 and Q2 profiles. J. Meteor. Soc. Japan, 84A, 133-149, https://doi.org/10.2151/jmsj.84A.133.

Lin, J., B. E. Mapes, M. Zhang, and M. Newman, 2004: Stratiform precipitation, vertical heating profiles, and the Madden-Julian oscillation. J. Atmos. Sci., 61, 296-309, https://doi.org/10.1175/ 1520-0469(2004)061<0296:SPVHPA $>2.0$. CO;2.

Marinescu, P., S. C. van den Heever, S. Saleeby, and S. Kreidenweis, 2016: The microphysical contributions to and evolution of latent heating profiles in two MC3E MCSs. J. Geophys. Res. Atmos., 121, 7913-7935, https://doi.org/10.1002/2016JD024762.

Medeiros, B., L. Nuijens, C. Antoniazzi, and B. Stevens, 2010: Lowlatitude boundary layer clouds as seen by CALIPSO. J. Geophys. Res., 115, D23207, https://doi.org/10.1029/2010JD014437.

Mellor, G. L., and T. Yamada, 1982: Development of a turbulence closure model for geophysical fluid problems. Rev. Geophys. Space Phys., 20, 851-875, https://doi.org/10.1029/RG020i004p00851.

Mlawer, E. J., S. J. Taubman, P. D. Brown, M. J. Iacono, and S. A. Clough, 1997: Radiative transfer for inhomogeneous atmospheres: RRTM, a validated correlated-k model for the longwave.J. Geophys. Res., 102, 16663-16682, https://doi.org/10.1029/97JD00237.

Oh, J.-H., B.-M. Kim, K.-Y. Kim, H.-J. Song, and G.-H. Lim, 2013: The impact of the diurnal cycle on the MJO over the Maritime Continent: A modeling study assimilating TRMM rain rate into global analysis. Climate Dyn., 40, 893-911, https://doi.org/ 10.1007/s00382-012-1419-8.

Peatman, S. C., A. J. Matthews, and D. P. Stevens, 2014: Propagation of the Madden-Julian Oscillation through the Maritime Continent and scale interaction with the diurnal cycle of precipitation. Quart. J. Roy. Meteor. Soc., 140, 814-825, https:// doi.org/10.1002/qj.2161.

Rauniyar, S. P., and K. J. E. Walsh, 2013: Scale interaction of the diurnal cycle of rainfall over the MC and Australia: Influence of the MJO. J. Climate, 26, 1304-1321, https://doi.org/10.1175/JCLI-D-12-00124.1.

Rotunno, R., 1983: On the linear theory of the land and sea breeze. J. Atmos. Sci., 40, 1999-2009, https://doi.org/10.1175/ 1520-0469(1983)040<1999:OTLTOT > 2.0.CO;2.

Shige, S., Y. N. Takayabu, W.-K. Tao, and D. E. Johnson, 2004: Spectral retrieval of latent heating profiles from TRMM PR data. Part I: Development of a model-based algorithm. J. Appl. Meteor., 43, 1095-1113, https://doi.org/10.1175/ 1520-0450(2004)043<1095:SROLHP > 2.0.CO;2.

Tan, J., C. Jakob, and T. P. Lane, 2013: On the identification of the large-scale properties of tropical convection using cloud regimes. J. Climate, 26, 6618-6632, https://doi.org/10.1175/JCLI-D-12-00624.1.

Tang, S., and Coauthors, 2016: Large-scale vertical velocity, diabatic heating and drying profiles associated with seasonal and diurnal variations of convective systems observed in the GoAmazon2014/5 experiment. Atmos. Chem. Phys., 16, 14249 14264, https://doi.org/10.5194/acp-16-14249-2016.

Tao, W.-K., S. Lang, J. Simpson, and R. Adler, 1993: Retrieval algorithms for estimating the vertical profiles of latent heat release: Their applications for TRMM. J. Meteor. Soc. Japan, 71, 685-700, https://doi.org/10.2151/jmsj1965.71.6_685. , and Coauthors, 2006: Retrieval of latent heating from TRMM measurements. Bull. Amer. Meteor. Soc., 87, 15551572, https://doi.org/10.1175/BAMS-87-11-1555.

TRMM Science Team, 2011: TRMM 3G25: Gridded Oribital Spectral Latent Heating Profiles L3 1.5 hours 0.5 degree $\mathrm{x} 0.5$ degree 
V7. NASA GSFC, http://disc.gsfc.nasa.gov/datacollection/ TRMM_3G25_V7.shtml.

Tropical Rainfall Measuring Mission, 2011: TRMM_3B42: TRMM (TMPA) rainfall estimate L3 3 hour 0.25 degree $\times 0.25$ degree V7. NASA GSFC, https://disc.gsfc.nasa.gov/datacollection/ TRMM_3B42_7.html.

Vincent, C. L., and T. P. Lane, 2016a: Evolution of the diurnal precipitation cycle with the passage of a Madden-Julian oscillation event through the Maritime Continent. Mon. Wea. Rev., 144, 1983-2005, https://doi.org/10.1175/MWR-D-15-0326.1.

, and $-2016 \mathrm{~b}$ : Maritime Continent Austral summer climatology v1.0. NCI National Research Data Collection, accessed 1 May 2018, https://doi.org/10.4225/41/5850b633c54ed.

, and - 2017: A 10-year austral summer climatology of observed and modeled intraseasonal, mesoscale, and diurnal variations over the Maritime Continent. J. Climate, 30, 38073828, https://doi.org/10.1175/JCLI-D-16-0688.1.

Wheeler, M. C., and H. H. Hendon, 2004: An all-season realtime multivariate MJO index: Development of an index for monitoring and prediction. Mon. Wea. Rev., 132, 1917-1932, https://doi.org/10.1175/1520-0493(2004)132<1917: AARMMI>2.0.CO;2.

Xie, S., T. Hume, C. Jakob, S. A. Klein, R. B. McCoy, and M. Zhang, 2010: Observed large-scale structures and diabatic heating and drying profiles during TWP-ICE. J. Climate, 23 , 57-79, https://doi.org/10.1175/2009JCLI3071.1.

Yanai, M., S. Esbensen, and J.-H. Chu, 1973: Determination of bulk properties of tropical cloud clusters from large-scale heat and moisture budgets. J. Atmos. Sci., 30, 611-627, https://doi.org/ 10.1175/1520-0469(1973)030<0611:DOBPOT>2.0.CO;2. 